\title{
Surgical Management of Larges Goiters in the ENT Department of CHU Mother and Child "Luxembourg"
} \author{
Boubacary Guindo4, Nagnouma Camara4, Mamadou Karim Touré5, Mahmoud Cissé1, \\ Amadou Djibo6, Youssouf Djigui Diakité6, Boubacar Sanogo', Mohamed Amadou Kéïta4 \\ ${ }^{1}$ ENT and Head and Neck Surgery Department, CHU Mother-Child "Luxembourg”, Bamako, Mali \\ ${ }^{2}$ ENT and Head and Neck Surgery Department, Reference Health Center District V, Bamako, Mali \\ ${ }^{3}$ Laboratory of Anatomy of the Faculty of Medicine and Odontostomatology, Bamako, Mali \\ ${ }^{4}$ ENT and Head and Neck Surgery Department, CHU Gabriel Toure, Bamako, Mali \\ ${ }^{5}$ Department of Anesthesia Resuscitation CHU Mother-Child "Luxembourg", Bamako, Mali \\ ${ }^{6}$ Department of Endocrinology, Mother-Child University Hospital “Luxembourg”, Bamako, Mali \\ Email: *ysidibe2002@gmail.com
}

Youssouf Sidibé1, Abdoul Wahab Haidara1, Djibril Samaké2, Abdoulaye Kanté3, Siaka Soumaoro",

How to cite this paper: Sidibé, Y., Haidara, A.W., Samaké, D., Kanté, A., Soumaoro, S., Guindo, B., Camara, N., Touré, M.K., Cissé, M., Djibo, A., Diakité, Y.D., Sanogo, B. and Kéita, M.A. (2019) Surgical Management of Larges Goiters in the ENT Department of CHU Mother and Child "Luxembourg". International Journal of Otolaryngology and Head \& Neck Surgery, 8, 139-149.

https://doi.org/10.4236/ijohns.2019.84016

Received: April 26, 2019

Accepted: July 19, 2019

Published: July 22, 2019

Copyright $\odot 2019$ by author(s) and Scientific Research Publishing Inc. This work is licensed under the Creative Commons Attribution International License (CC BY 4.0).

http://creativecommons.org/licenses/by/4.0/

\begin{abstract}
Objectives: To study the clinical and therapeutic profiles of voluminous goiter. Patients and Methods: We carried out a descriptive and prospective study, relating to a series of 30 cases of voluminous goitre, collected in the Department of Otorhinolaryngology and cervicofacial surgery (ENT and CCF) of the CHU Luxembourg Mother Child of Bamako. It has been spread over a period of 4 years from January 2015 to December 2018. Patients of all ages operated for large goitre at the ENT Department of CHU Luxembourg Mother Enfant were included. Results: In 4 years we collected 30 cases of voluminous goitre; during this period we realized 180 thyroidectomies, i.e. frequency of $16.67 \%$. The average age was 51.37 years with an extreme ranging from 38 to 65 years. Females were common in $66.7 \%$ with a sex ratio of 0.50 . The long duration of evolution has been 40 years. The sign of compression was found in $85.7 \%$. The physical examination found a mobile swelling, hard and painless in all patients with normal endolaryngeal examination; there was no cervical lymphadenopathy. The lower dipping pole was found in 5 cases on CT. All our patients were euthyroid. The classification of TIRADS 2 was found in $80.0 \%$ of cases. Total thyroidectomy was frequent with $50.0 \%$ of cases. The average weight of the operative specimen was $586.67 \mathrm{~g}$ with extremes ranging from $500 \mathrm{~g}$ to $800 \mathrm{~g}$. The size of the operative piece of $14 \mathrm{~cm}$ was the longest. Injury of internal jugular vein was found in $26.7 \%$ of cases. Colloid adenoma of the thyroid was found in $100 \%$ of cases, postoperative
\end{abstract}


complications of the type of hematoma of the lodge in $3.3 \%$ of cases, the release of the operative wound in $10 \%$ of cases local superinfection in $7.1 \%$. Signs of hypothyroidism were common with $50.0 \%$. Postoperative nasofibroscopy found good vocal fold mobility in all patients. Conclusion: The large goiters have become rare because of the early management of thyroid nodule. Its management must allow the prevention of recurrent and parathyroid morbidity.

\section{Keywords}

Thyroid, Large Goiter, Thyroidectomy

\section{Introduction}

Goitre refers to diffuse normal thyroid hypertrophies (absence of hyper- or hypothyroidism), non-inflammatory (excluding thyroiditis), and non-cancerous, It consists of initially homogeneous thyroid hyperplasia, clinically latent [1], Radiologically it is defined by an ultrasound thyroid volume of $18 \mathrm{ml}$ in women, 20 $\mathrm{ml}$ in men [2]. The proportion of goiter is 4 to 5 times higher than in females [1] [3].

The classification of goiters has been made by WHO ranging from stage I to stage III. Bulky goitre or goiter type III is defined as being visible more than five meters away. The semiological richness is the corollary of an increase in volume as well as its multi-nodular character. This increase causes compression at the tracheal, oesophageal, recurrent nerve and deep veins. This results in a clinical spectrum characterized by dyspnoea, dysphonia or even an upper vena cava syndrome [4].

These symptoms appear gradually and are life-threatening, especially when the development is intra-thoracic [5].

Imaging assessments, namely ultrasound, $\mathrm{CT}$ and chest and lateral radiography, form the bedrock of giant goiter management. They allow highlighting signs of malignancy, to weave the relation with the neighboring organs and to objectify an intrathoracic prolongation [1] [2].

Thyroid surgery has a privileged place in the treatment of multiple thyroid diseases, especially in cases of thyroid cancer, but also bulky nodule, compressive goitre, diving or toxic [6].

It is up to the surgeon to set up a protocol for surgical management. This requires a multidimensional approach [7].

The nosology of giant goiter remains a subject little discussed by the literature [6] [8]. Its management is a problem of integration efficiency in the recommendations on giant goiter as an entity. The multiplicity of the ratio of the thyroid gland with the other neighboring organs and the development of a giant goiter in this restricted cervical space is the corollary of the phenomenon of compression and difficult intubation [6] [8]. 
In view of the problem posed by the management of giant goiters by surgeons, we brought elements contributing to the rationalization of a therapeutic strategy that could contribute to the reduction of the postoperative complication rate.

\section{Patients and Method}

We conducted a descriptive and prospective study, involving a series of 30 cases of giant goiter, collected in the department of otorhinolaryngology and cervicofacial surgery (ENT and CCF) of CHU Mere Enfant Luxenbourg, Bamako, over a period of 4 years from June 2015 to June 2018. We are based on the clinical and radiological criteria for the diagnosis of large goiters.

Have been included: Patients of all ages operated on for a large goitre at the ENT department of CHU Mère enfant luxanbourg whose weight of the surgical specimen was greater than or equal to $500 \mathrm{mg}$. Patients whose mobility of the larynx is preserved preoperatively.

Have been excluded: Inapplicable files, Non operated patients, Thyroid cancers.

\subsection{Variables Studied}

Sociodemographic status: age, sex, antecedent

$>$ Clinical aspects: functional signs, physical signs

$>$ Paraclinical data: biological assessment, Cervical ultrasound and CT

Postoperative results: histological examination of the operative specimen

$>$ Patients undergoing total thyroidectomy received thyroid hormone supplementation.

\subsection{The Operative Technique}

All patients were operated under general anesthesia

$>$ The approach was the classic route of thyroidectomy

$>$ Opening of the white line

$>$ Ligation of the vessels of the superior pole, Identification and preservation of the superior parathyroid

Cricopharyngeal muscle exposure

$>$ The recurrent nerve is searched after palpation of the small horn of the thyroid cartilage

$>$ The nerve was dissected until it emerged in the chest; ligation of the branches of the inferior thyroid artery, identification and preservation of the lower parathyroid

$>$ Depending on which part of the gland is affected by loboisthmectomy or total thyroidectomy

The closure was carried out in two planes

Analysis and data processing: An investigation sheet was established, the consent of patients was previously obtained to participate in the study. The data has been computerized using software specialized in statistical processing "SPSS 
21.0 French version", and the data entry on Word 2013.

\section{Results}

\subsection{Epidemiological Aspects}

The frequency: In 4 years we collected 30 cases of voluminous goitre, during this period we performed 180 thyroidectomies, a frequency of $16.67 \%$ of cases,

The mean age was 51.37 years with an extreme ranging from 37 to 65 years and a standard deviation of 7.97 (Table 1). Females were common in $66.7 \%$ of cases with a sex ratio 0.50 .

\subsection{Clinical Aspects}

Reason for consultation: All patients consulted for cervical swelling.

The duration of evolution: The long duration of evolution was 40 years in one case the average duration was 18, 20 years.

The family history of goiter was found in 4 cases or $13.3 \%$.

Signs of compression: The sign of compression was found in $85.7 \%$ (Table 2).

\subsection{The Physical Examination}

The physical examination found a mobile swelling, hard and painless in all patients is $100 \%$, Goitre was unilateral in $26.7 \%$ of cases (Figure 1 ) and bilateral in $73.3 \%$ of cases (Figure 2). Endolaryngeal examination was normal in all patients, there was no cervical lymphadenopathy.

Table 1. The distribution of patients by age.

\begin{tabular}{ccc}
\hline Age & Effective & Percentage \% \\
\hline$[30-40]$ & 2 & 6.67 \\
{$[40-50]$} & 12 & 40.00 \\
{$[50-60]$} & 8 & 26.67 \\
{$[60-70]$} & 8 & 26.67 \\
Total & 30 & 100 \\
\hline
\end{tabular}

Table 2. Distribution of patients according to signs of compression.

\begin{tabular}{ccc}
\hline Compression Signs & Effective & Percentage \\
\hline Isolated dysphony & 1 & 7.1 \\
Isolated dysphagia & 2 & 14.3 \\
Isolated dyspnea & 4 & 28.6 \\
Dysphagia + dyspnea & 4 & 28.6 \\
Dysphagia + dyspnea + dysphagia & 1 & 7.1 \\
Total & 25 & 85.7
\end{tabular}




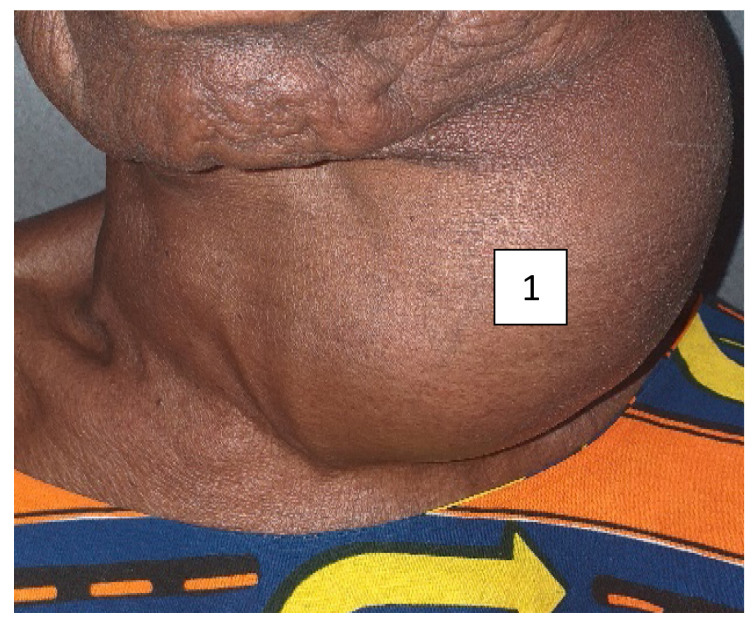

Figure 1. Left thyroid swelling. 1-left lobe.

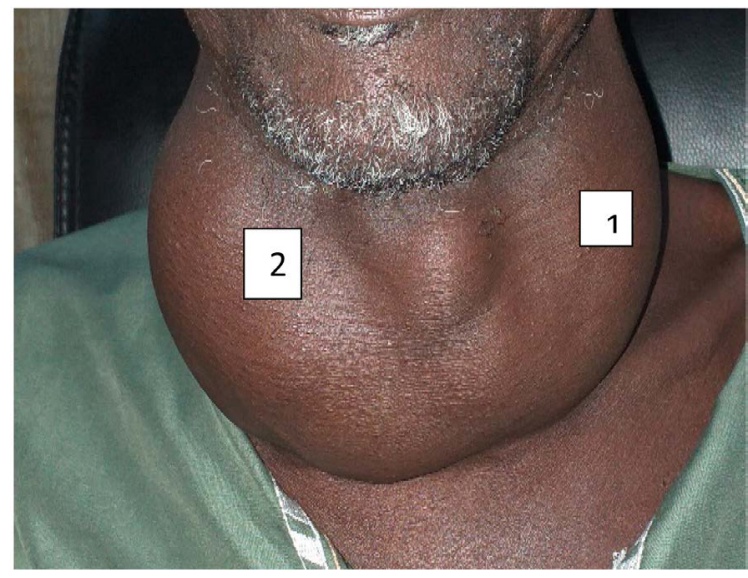

Figure 2. Bilateral thyroid tumefaction. 1-left lobe; 2-right lobe.

\subsection{Paraclinical Aspects}

The lower diving pole was found in 12 cases at CT, All our patients were euthyroid.

The classification of TIRADS 2 was found in $80.0 \%$ of cases, Filtration was not performed in any of our patients (Table 3).

\subsection{Therapeutic Aspect}

Surgical treatment: Total thyroidectomy was common in $50.0 \%$ of cases (Table 4).

Extreme weight was $500 \mathrm{~g}$ and $800 \mathrm{~g}$ with an average of $586.67 \mathrm{~g}$ and a standard deviation of 81.93 (Figure 3), The size of the largest workpiece was $14 \mathrm{~cm}$, The internal jugular vein lesion was found in 8 cases, ie $26.7 \%$, Colloid adenoma of the thyroid was found with $100 \%$ of cases.

The postoperative course: We noted a case of the hematoma of the box is $3.3 \%$; 3 cases of the release of the operative wound is $10 \%$ and 2 cases the superinfection is $7.1 \%$. Signs of hypothyroidism were common with $50.0 \%$ and 
Table 3. Distribution of patients according to paraclinical examination.

\begin{tabular}{ccc}
\hline Paraclinical examinations & Effective & Percentage \\
\hline CERVICAL CT & 12 & 40.0 \\
CERVICAL ULTRASOUND & 30 & 100.0 \\
TSH us-T4 & 30 & 100.0 \\
\hline
\end{tabular}

Table 4. Distribution of patients by type of surgery.

\begin{tabular}{ccc}
\hline Surgical treatment & Effective & Percentage \\
\hline Right Loboisthmectomy & 3 & 10.0 \\
Left Loboisthmectomy & 5 & 16.7 \\
Subtotal thyroidectomy & 7 & 23.3 \\
Total thyroidectomy & 15 & $\mathbf{5 0 . 0}$ \\
Total & 30 & 100.0 \\
\hline
\end{tabular}

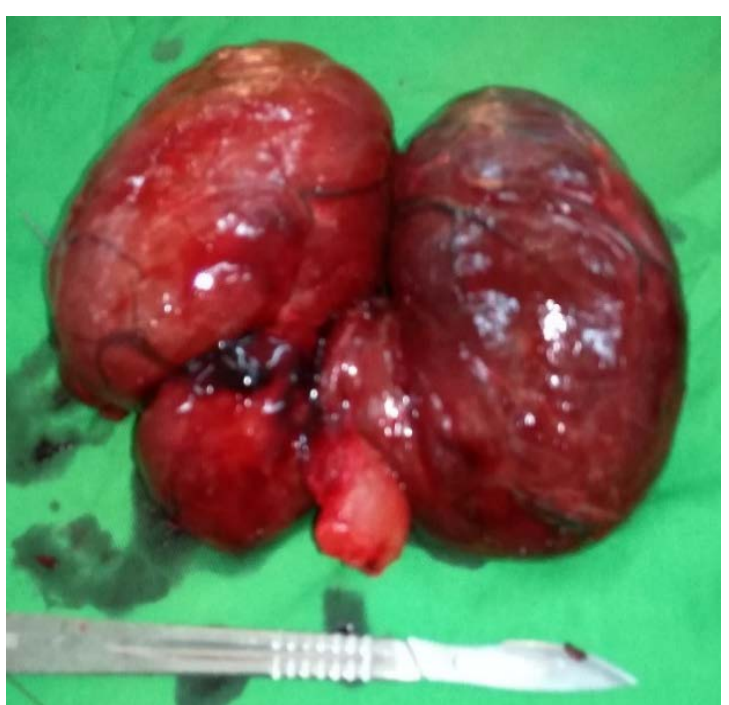

Figure 3. Operative part of a total thyroidectomy weighing $800 \mathrm{~g}$.

hypocalcemia in $26.7 \%$ of cases, Postoperative nasofibroscopy found good vocal fold mobility in all patients.

\section{Comments and Discussion}

\subsection{Socio-Epidemiological Aspects}

During 4 years we realized in the ENT and CCF Department of the Mother-Child Hospital Luxembourg 180 thyroidectomies including 30 cases of voluminous goitre, a frequency of $16.67 \%$ of cases.

The frequency of large goiters is poorly reported in the literature [9], The few reported cases concerned clinical cases not reporting the frequency of giant goiters within goiter. This observation highlights the rarity of cases of giant goiter unlike our series, In the West they are rare because of the early consultations of 
patients [10].

The average age of our patients is close to that of MAKEIEFF $M$ who was 60 years old [9], KEITA MA [11] and KEITA I did not share this finding, the average age of 40.9 years is lower than that of our series. The female predominance is the preserve of goitres reported by KEITA MA [11] and MAKEIEFF $M$ [9].

The age of goitre progression according to KEITA $M A$ [11] has been more than 20 years in $53 \%$ of cases and according to MAKEIEFF $M$ has been $25 \%$ for 15 years, in $25 \%$ of cases for more than 30 years and in $25 \%$ of cases for less than a year. The long evolution time has been 40 years in our series.

\subsection{Clinical Aspects}

Clinical findings in our patients have revealed a mobile swelling. However, signs of compression such as dysphagia and dyspnea of decubitus due to the development of goitre have been reported in our patients as in other series [9], The characteristics of the swelling, the associated signs and the laryngeal mobility make it possible to direct the ENT surgeon to make histological hypotheses,

The family history of goiter was found in 4 cases, or $13.3 \%$, unlike the KEITA $I$ series which reported $13.7 \%$ [12], In front of this antecedent one must look for the medullary carcinoma, a deficiency in iodine [5].

\subsection{Paraclinical Aspects}

Paraclinical explorations of large goiters are based on tomodensitometry, thyroid echography, and thyroid hormone testing [5], The cervico-mediastinal computed tomography performed in our case according to the signs of compression made it possible to determine the relation with the vasculo-nervous axis and the plunging nature of the goitre (Figure 4). She has been an indicator in the recurrence for the surgeon.

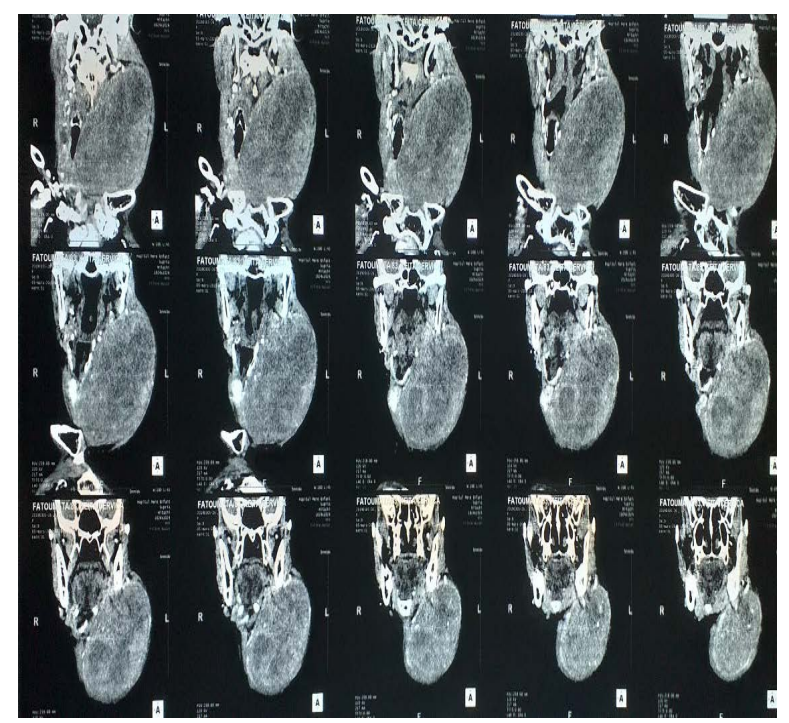

Figure 4. CT of thyroid swelling developed at the expense of left lobe. 
Computed tomography has not been systematic in the MAKEIEFF M series, it has made it possible to recover the plunging character of goiter as well as MRI [9]. The esogastroduodenal transit was indicated by MAKEIEFF $M$ in cases of goitre associated with dysphagia [9], Computed tomography was performed in four (4) cases corresponding to diving goitres.

Cervico-mediastinal CT is part of the extension assessment of thyroid cancers and large and/or plunging goitres [1] [5], MRI has several strengths: excellent tissue contrast; no interference of gadolinium with thyroid function and isotopic explorations. These indications of choice are therefore: precise exploration in case of goiter goiter; the extension assessment of thyroid cancers; the search for post-surgical tumor recurrence [5].

The ultrasound criteria were of a contribution in the management of giant goiters, giving the criteria of malignancy or benignity according to the classification TIRADS.

The main criteria predicting malignancy: are the solid character and hypoechoic appearance, micro-calcifications, irregular contour or fuzzy boundaries, absence of a peri-nodular halo, nodule higher than broad, intra-nodular vascularization. It is important to note that for the moment, none of these studies has made it possible to define the relative importance of these different criteria [5] [13].

\subsection{Therapeutics Aspects}

\section{Access way and type of thyroidectomy}

All our patients were operated under general anesthesia. The approach was an exclusive anterior cervicotomy. Total thyroidectomy was the most frequent indication with $50.0 \%$ in our case as in the series of KEITE A who reported $60 \%$ of cases [14] and in the series MOULOUDJI L and MAHMOUDI $H$ who reported $89 \%$ of cases [15], In the BENBAKH M. and al series, total thyroidectomy in 98\% [16], In other series the thyroidectomy was partial [17]. Ultrasound data based on the TIRADS classification guided our therapeutic indications.

In the MAKEIEFF $M$ series the mean weight of goiter was 175 grams with a maximum of 800 grams and the size was between 6 and $15 \mathrm{~cm}$ for the largest [9],

In the BENBAKH $\mathrm{M}$ et al series, the average weight of goiters was 205 grams with a maximum of 820 grams. The size was between $5.3 \mathrm{~cm}$ and $19 \mathrm{~cm}$ for the largest [16]. For Koumare AK; the average weight of goitres was 320 grams [17]. These data are close to those of our patients. In patients with signs of compression in our series, goitre was voluminous. The same observation has been noted in some authors [9].

The volume of goitre can change the operative sequence. The problems associated with diving and giant goitre are of a recurrent and parathyroid nature. Prevention of recurrent morbidity is imperative [5].

\subsection{Operating Incidents}

In giant goiters, the exteriorization of the gland towards the midline to perform the recurrent search is difficult. This act is responsible for stretching and nerve 
traction. The retrograde pathway was the main mode of dissection. In the absence of a recommendation on this subject we prioritized it. Several authors agree that the recurrent approach sought is the retrograde pathway in cases of giant goiter, diving and in cases where the classical path is impossible [18], It always allows to locate the nerve without stretching,

Thyroid surgery is the prerogative of the complications we have identified cases of jugular injury, These are goitres that compressed the vasculo-nervous axis with adherence to a thyroid capsule, Intraoperative haemorrhage was observed in the KOUMARE AK series in 12\% [17], Several factors explain the hemorrhagic risk of giant goiters. These include hypervascularization of the thyroid parenchyma, more pronounced dilation of the peripheral vessels, the very close relationship with the jugulocarotidian axis and overflow on the aortic arch [6] [17].

\section{$>$ Postoperative follow-ups}

Final recurrent paralysis and hypocalcemia were noted in the KOUMARE AK series. In our case, no definitive recurrent and parathyroid lesions were noted. Hypocalcemia varies in the literature between $1.6 \%$ to $50 \%$ according to JAFARI $M$ [19]. Whether transitory or definitive, is a usual complication [6], It occurs as a result of parathyroid parenchymal excision and devascularization of the parathyroid glands at the time of dissection. Hypocalcemia was transient in $7.1 \%$ in our series.

The operative sequences in some cases were enamelled with hypothyroidism. Total thyroidectomy exposes the same mortality and morbidity risks as subtotal and prevents the risk of tumor recurrence [20], In our series hypothyroidism following total thyroidectomy is the illustration of treatment nonobservance due to low income of the population.

The benign histological nature concerned the colloid adenoma with $100 \%$ of cases. This histological aspect corroborates with that of MAKEIEFF M [9] MOULOUDJI L and MAHMOUDI $\mathrm{H}$ which reported $97.46 \%$ [15] contrary to the series of KEITA I [12] which found colloid adenoma in $63.8 \%$ of cases.

\section{Conclusion}

The large goiters have become rare because of the early management of thyroid nodule. They impose surgical excision most often cervical in our context. A systematic clinical and radiological examination makes it possible to make the diagnosis. Its management must allow the prevention of recurrent and parathyroid morbidity.

\section{Conflicts of Interest}

The authors declare no conflicts of interest regarding the publication of this paper.

\section{References}

[1] Wemeau, J.L. (2010) Épidémiologie des maladies de la thyroïde. In: Les maladies de 
la thyrö̈de, Elsevier Masson, Paris, 49-52.

https://doi.org/10.1016/B978-2-294-07464-6.50006-9

[2] Tramalloni, J. and Wemeau, J.L. (2012) Consensus français sur la prise en charge du nodule thyrö̈dien: Ce que le radiologue doit connaître. EMC-Radiologie et imagerie médicale-Cardiovasculaire-Thoracique-Cervicale, 7, 1-18.

https://doi.org/10.1016/S1879-8535(12)60946-5

[3] Dravo, Y.J. (1995) Epidémiologie et prise en charge des goitres en milieu hospitalier à Ouagadougou. Médecine d' Afrique Noire, 42, 152-157.

[4] Courtillot, C., Petit, R., Ambonville, C., Touraine, P. and Leenhardt, L. (2008) Pathologies bénignes de la thyroidie. In: Brasnu, D., Ayache, D., Hans, S. and Panon, H.D., Eds., Traité d ORL. Médecine Science Flammarion, Paris, 80-691.

[5] Guerrier, B., Zanaret, M., Le Clech, G. and Santini, J. (2006) Chirurgie de la thyroïde et de la parathyroïde. Journal ORL Amplifon, 41, 208.

[6] Tran Ba Huy, P. and Kania, R. (2004) Thyroïdectomie. EMC-Chirurgie, 1, 187-210. https://doi.org/10.1016/j.emcchi.2004.02.003

[7] Clemençot, A., Jnana, M. and Koszutski, M. (2018) Détresse respiratoire aiguë: Un cas de goitre thyroïdien compressif. Journal Européen des Urgences et de Réanimation, 30, 38-40. https://doi.org/10.1016/j.jeurea.2018.04.001

[8] Duron, F. and Et Dubosclard, E. (2000) Goitres Simples. Encycl Méd Chir (Editions Scientifiques et Médicales Elsevier SAS, Paris, tous droits réservés), Endocrinologie-Nutrition, 10-007-A-10, $10 \mathrm{p}$.

[9] Makeieff, M., Marlier, F., Khudjadze, M., Garrel, R., et al. (2000) Les goitres plongeants. À propos de 212 cas. Annales de Chirurgie, 125, 18-25. https://doi.org/10.1016/S0001-4001(00)00117-3

[10] Colack, T., Akca, T., Kanik, A., Yapici, O. and Aydin, S. (2004) Total versus Subtotal Thyroidectomy for the Management of Benign Multinodulaire Goiter in an Endemic Region. ANZ Journal of Surgery, 74, 974-978. https://doi.org/10.1111/j.1445-1433.2004.03139.x

[11] Keita, M., Diango, D., Traore, C., Kamate, B. and Mohamed, A. (2007) Les goitres benins en ORL Aspect epidemiologiques et anatomocliques: Etude de 97 cas. Journal Tunisien d Chirurgie Cervico-Faciale, 18, 16-19.

https://doi.org/10.4314/jtdorl.v18i1.42039

[12] Keita, I. (2008) Les goitres nodulaires hyperthyroïdiens dans le service de chirurgie B du CHU du Point G: 274 cas. Thèse en médecine, University of Science, Technology and Technology of Bamako, Bamako, 102.

[13] Gilles, R. (2016) Nouveautés en échographie: Le score TI-RADS peut-il éviter la cytoponction? Le Journal ORL Amplifon, 29, 44.

[14] Keïta, A., Diallo, A.O., Fofana, M., et al. (2018) Thyroidectomy and Review of Literature: About 60 Cases at Donka National Hospital. International Journal of Development Research, 8, 19602-19601.

[15] Mouloudji, L. and Mahmoudi, H. (2017) La prise en charge chirurgicale du goitre. Etude rétrospective sur 79 cas au niveau du CHU de Bejaia, Alger, 186.

[16] Benbakh, M., Abou-Elfadl, M. and Rouadi, S. (2016) Goitres plongeants: Expérience du service à propos de 50 cas. Annales Françaises d'Oto-Rhino-Laryngologie et de Pathologie Cervico-Faciale, 133, 17-20. https://doi.org/10.1016/j.aforl.2015.01.011

[17] Koumare, A.K., et al. (2002) Goitres bénins en chirurgie au Mali (à propos de 815 cas). E-mémoires de l Académie Nationale de Chirurgie, 1, 1-6.

[18] Makeieff, M. and Guerrier, B. (2006) Dissection rétrograde du nerf récurrent dans la 
chirurgie thryoidienne. Fr ORL, 90, 203-209.

[19] Jafari, M., Pattou, F., Soudan, B., Devos, M., Truant, S., Mohiedine, T., et al. (2002) Etude prospective des facteurs prédictifs précoces de la survenue d'hypocalcémie définitive après thyroïdectomie bilatérale. Annales de Chirurgie, 127, 612-618. https://doi.org/10.1016/S0003-3944(02)00821-0

[20] Dener, C. (2002) Complications Rates after Operations for Benign Thyroid Disease. Acta Oto-Laryngologica, 4, 1090-1096.

https://doi.org/10.1080/000164802320396394 